\title{
Research on International Management Reform and Practice in University Teaching
}

\author{
Tao ZHOU ${ }^{1, a,{ }^{*}, \text { Xiao-Lu FANG }}{ }^{2, b}$, Juan CHEN $^{2, c}$, Yu-Xi YUAN ${ }^{1, d}$ \\ ${ }^{1}$ International Education Institute, North China Electric Power University, Beinong Rd., Changping \\ District, Beijing 102206, China \\ ${ }^{2}$ School of Nuclear Science and Engineering, North China Electric Power University, Beinong Rd., \\ Changping District, Beijing 102206, China

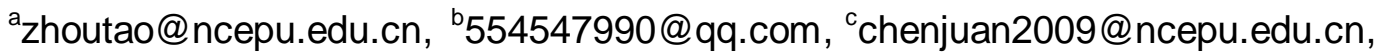 \\ damiyuxi@126.com \\ ${ }^{*}$ Corresponding author
}

Keywords: University teaching, Management, Education, Internationalization.

\begin{abstract}
The University Teaching Management internationalization is an important part of the university education internationalization, and is also an important way for university development. By analyzing the current internationalization situation of domestic and foreign universities, determine that the key of university teaching management internationalization is to determine the direction. Combined with international university model, propose to establish an international teaching management mechanism and system, the key is to combine the national conditions. Combined with the existing university system, propose to achieve university teaching management internationalization .The key issue is a smooth transition. Determine the internationalization of university teaching management should establish a well-functioning mechanism and system, avoid the dominance of the executive power, bicameral system is a form worth exploring. Determine that layer upon layer is responsible for the university teaching management internationalization, everybody is responsible for it, remove the specialized agencies, achieve grassroots leaders are responsible for responsibilities, set up a priority system for teaching . Actively promote, a smooth transition, democratic implement, and up to standard early.
\end{abstract}

\section{Introduction}

Higher Education in China along with China's reform and opening up has gone through ups and downs over thirty years, higher education including university teaching has made considerable progress during the period ,meanwhile, also has many problems. Currently, international issues of university teaching continue to be put forward, in fact this problem also has continuous development in the continuously exploring. The internationalization of university teaching is a key link in university teaching management internationalization[1]. How to practice, how to reform, in practice, different schools have different understanding and exploring, especially how to get the healthy development in the new normalof China's economy, needs to give enough attention and in-depth research. Only by doing top-level design, and theoretical guides, a better suitable development can be got, so China's higher education will be promising and can really cultivate proper socialist builders and successors.

\section{Values and goals}

The first step of internationalizing university education is the internationalization of teaching management. Without the internationalization of management, the internationalization of teaching itself will be limited, which could influence the effect of internationalizing university education. The internationalization of university teaching management has its important value and the overall goal which it must achieve. 
The internationalization of university teaching management is the basic requirement for the implementation of national policy.

With the transformation to powerful nation by big country, China has confirmed that in a long period of time the country would be in the stable development. Chinese 2010-2020 Education Development Plan points out, "exchange and cooperation with foreign countries should be strengthened. We should persevere in promoting the reform and development by opening up. Exchanges and cooperation of education in a multilevel and wide-ranging way should be carried out to improve the standards of internationalizing education in our country. Using international advanced education idea and education experience for reference could promote the development of education reform in China, and could also enhance the international status, influence and competitiveness of China's education. In order to adapt to the requirement which national economic and social demands from open-door policy, large quantities of international talents with international vision, familiar with the international rules, to participate in international affairs and international competition should be trained." National policy is clear. Combined with the requirements of current affairs, universities should carry out and achieve the national policy [2], as well as achieving the internationalization of university teaching management.

The internationalization of university teaching management is an inevitable trend to guide the development of universities.

International universities have much advanced experience and many universities have set out the aims of building a world-class university. Therefore, learning the advanced experience of international universities has become a target for many colleges and universities. Learning the advanced experience and other effective methods from international universities could be an important technique to promote and guide the development of domestic colleges and universities, which could also be a tendency of teaching management in colleges and universities. The internationalization means the advanced level which should be learned modestly. We have learned from the western countries and the Soviet Union before, and the development history of Chinese universities is a kind of learning history. As Chinese have a great capacity for learning, taking the international advanced teaching management experience for our own use will promote the progress and development of colleges and universities.

The internationalization of university teaching management is the fundamental impetus to the development of teachers.

As the precondition of the development of universities is the development of teachers, a good teaching environment is the success of the university teaching management. Therefore, the internationalization of university teaching management must be taken as the fundamental driving force to promote the development of teachers. The internationalization of the teaching management could arouse teachers' enthusiasm, improve their ability, and exert their maximum efficiency in the environment [3]. Just as flowers are competing in splendor in summer, teachers require internationalization and reform themselves. The requirement should come from teachers' own will and should also meet the need of environment. Then it could be a successful teaching management mode.

The internationalization of university teaching management is the necessary way to improve students' quality.

Basically, the internationalization of university teaching management is for students to improve their competitiveness and basic quality, which is the starting point as well as the end-result. In the 2007 annual report of the World Trade Organization (WTO) and the International Labor Organization (ILO), it was pointed out that universities should make their graduates have the ability to participate in global society actively, and make them possess the language skills to communicate effectively, and make them capable of dealing with different mechanism and different culture. The international university teaching management draws lessons from the international advanced way of teaching management to enhance the students' autonomy. Students under this kind of management must have stronger body and greater ability to face the international environment, just like the seagulls fly higher during the storm.

Especially it is important to note that the internationalization of university teaching management, has its advantages, and should be utilized actively. But the university teaching management 
internationalization is not a panacea for solving all the problems, and can not be the thing once and for all. It should be improved and developed continuously. Thinking that all the problems can be solved as long as internationalization is achieved, Is another kind of behavior of a wholesale westernization, this will cause the result of not digesting foreign things, and ultimately affect the internationalization of higher education itself[4], affect the education and training for people.

Define objective, identify the direction, get better development.The overall goal of university teaching management internationalization should be:put forward university teaching management mechanism and system solutions according with China's national conditions and adopting international practices[5]; establish evaluation index and method, put forward the concrete process of university teaching internationalization.

\section{Problems and Solutions}

Analyse and research the internationalization current situation of universities at home and abroad [6], the key problem in determining the direction of universities' teaching management internationalization is that unified standards are needed or not.

There are big differences in teaching management mode between Chinese universities and foreign universities. The story of that year is that from scholastic year system to credit system what Chinese universities had learned was the combination of scholastic year system and credit system.Now, the internationalization way is varied in different universities, there are colleges with independent legal entities, but more universities choose to found international education academy in their school. The current situation of universities' teaching management internationalization is a trend; there is not a unified standard.Western schoolar Jane Knight gave a neutral definition. He said, internationalization of higher education is a process to integrate the international and cross-cultural aspects into the school teaching, scientific research and service functions.By this definition universities'teaching management is to integrate the international and cross-cultural aspects into teaching management.Hence the current key problem is not to determine a unified standard of universities' internationalization but to determine the direction of efforts' direction of culture.In this cultural concept to reform, to lead the teaching management.Rather than go with the flow, learn something fur, craw follow other person forever,this is the real internationalization of universities, teaching management concept and also the real realization of universities' teaching management internationalization. This also must be the new practice of higher teaching management internationalization according to the education program planning in the new normal.

\section{Combined with international university model, put forward International teaching management mechanism and system. The heart of the matter is how to combine them with our national conditions.}

Many of the advanced universities in the world have been international with a ready-made international basic pattern; especially the teaching management mode has been mature. On the premise of careful study, absorb the teaching management mode dialectically is the key to the question. Simply copy whole of the other's experience is most infeasible and it may result in some problems just like dyspepsia. We must consider its background of implementation on the basis of understanding the management's connotation. Compared with the new normal of China's basic national conditions and the development of economy to absorb other's experience dialectically, combine the international advanced experience with some of our management mode which proved to be effective by practice flexibly. In this way we can create a teaching management system and mechanism which adapt to China's actual conditions and Internationalization. Only this system and mechanism is being not acclimatized and can develop healthily. On this situation, China's actual conditions are key and the soil. That is to say, China's actual conditions are in the first place in the process of China's universities' teaching management internationalization and then is world's. Without China, there is no foundation. 
Combined with existing university system, put forward how to ralize the internationalization of universities' teaching management. The heart of the matter is the smooth transition.

Existing Chinese university has developed for several decades, some of which have been one hundred years, by rights should be mature, and experienced.An university can exist in the ups and downs indicates its rationality of the university's teaching management.Therefore,we must seize this fundamental, and this is the starting point. It should be considered that university will be international after all and the teaching management mode will be international, it determines that we must absorb foreign good experience. Now, there are many management measures not harmonious, even in conflict with each other under the existing pattern. Therefore, there must be a smooth transition. Slow work yields fine products, reform and innovation are needed. But the action steps must gradually and smoothly and the process of teaching management mode's internationalization should be propelled harmoniously.The people and work should be good, the reform of university's teaching management mode would get to sneak in the night with the breeze, thin breathed result in smooth thing.

Analyse the hierarchical mechanism of university teaching management internationalization and determine the evaluation criteria and benign self development mechanism.

Reform of university teaching management internationalization also must be hierarchical, it is a holistic and methodic work. Throughout International universities we can find that Internationalization is not only the thing to one department, but also all the hierarchies' internationalization.Therefore, the real internationalization of a university's teaching management mode is from school to academy ,to teaching and research office, it should be all departments' internationalization.In other words, the world's is China's and China's is also the world's. Use the same teaching management mode for Chinese and foreign students. In this way, we should set up a corresponding evaluation criteria to every hierarchies' teaching management mode and found a benign mechanism of self -development. Every hierarchy strives for internationalization conforms to the target and direction of their own development, it's not imposed. So university's teaching management mode can be on track of benign development.

\section{Method and approach}

\section{Establish the direction and measuring standard of university teaching management internationalization.}

To realize the internationalization of university teaching, the first thing to realize is internationalization of university teaching management. This is the precondition of work. Define the efforts direction of university teaching management internationalization is very important. The internationalization of management is modern in the first place, management style should invigorate large enterprises while relaxing control over small ones, management loose. Do not manage all the things, no matter the things are small or large, important or not important. Manage the main parts, give full play to the enthusiasm of grass-roots level college and teachers. Meanwhile, grassroots colleges are also required that no Affairs should be transferred, if the school don't deal. The college will have to deal more, instead, increase more burdens on teachers, this is not feasible. The highest level of management is inaction. On the premise of guaranteeing some fewer but better basic courses, give full play to the enthusiasm of teachers, give students to choosing right. Real Credit System, real elastic system on schooling, actively create a harmonious atmosphere of success. Good internationalization is magnanimous, democracy and freedom, and this is the standard. Don't let the standard be quantitative scoring, don't do all the things in the same way, if so, it is taking a form to change another kind of form stiffly in fact, this lacks diversity, it will surely suppress creativity in practice, and it also violates the original intention of internationalization. Therefore, here the internationalization of the teaching management is a kind of direction worthing of efforts, and implementation standard of a principle.

Establish the management mechanism and system the internationalization management of university teaching should have.

The internationalization of university teaching management is relative and absolute. So, management 
mechanism and system should not only be relatively stable, but continuous development. Stability can make us familiar, can make everybody understand the purpose, it is the fruit that can be got through efforts; meanwhile, in order to avoid rigidit, get a continuous development, flowing water does not rot. On the basis of the original, consider Beijing with Chinese characteristics, consider the new normal development and absorb foreign advanced experience dialectically when constructing university teaching management system and mechanism. To make clear decision-making in teaching management of professors and Teaching Committee of democratic, it should determine to make administrative power being out decision, avoiding rushed decision, avoiding personal decision, and avoiding the administrative intervention. In fact, there is a way to solve this problem, playing combined action of Party committee decision-making and professor meeting. This is a reliable way for the development of democracy with Chinese characteristics. In this way, not only having democracy and freedom, but having a clear direction, not only adhering to the political orientation, but the local level is active. At present, giving power to the college is a mistake, college intercepting power shows more inequities, causing dean alone big, manage more finely, less conducive to development. Delegate authority to professor teaching committee, adhere to the bicameralism. The innovating system and mechanism, will generate the new mode of the teaching management internationalization with Chinese characteristics, coruscate vitality and passion of professors.

\section{The concrete process of the internationalization of university teaching management}

University teaching management internationalization is not achieved overnight; need a smooth transition step by step. At present, the most urgent things should be to do the following.

First, Office of Academic Affairs should be changed into the institute of education and teaching, increasing international responsibilities, ruling over the international education college. The institute of international education is not necessary.

Second, the professional school mission should have some internationalization task; an international education teaching secretary is needed. Each college has annual international task performance targets.

Third, the university teaching committee should work at least once a year to study internationalization, held seminars, develop policies and system, and promote internationalization.

Forth, the Organization Department must make sure that the Vice-President in charge of venerable Associate Professorial person with higher positional title. And the person must be ranked in front of the other vice-president ensure the priority of the education Vice-President.

Fifth, every college should establish Education and Teaching Committee and give them international duties clearly, form Bicameral system with the General Party Branch Committee of the university, and the administration of the university should not interfere the policy.

Sixth, every college should not inhibit the development of the teachers with executive powers, should respect the right of the teachers, and the teachers should play teaching capability democratically and freely.

\section{Conclusions}

The University Teaching Management internationalization is an important part of university development, actively promote, a smooth transition, democratic implement, and up to standard early.

First, determining the internationalization of university teaching management is an important direction of the university, modernization is the premise, and respect is purpose, with a smooth and democratic transition.

Second, determine the internationalization of university teaching management should establish a well-functioning mechanism and system, avoid the dominance of the executive power, bicameral system is a form worth exploring.

Third, determine that layer upon layer is responsible for the Determine the internationalization of university teaching management is an important direction of the school, teaching management internationalization, everybody is responsible for it, remove the specialized agencies, achieve grassroots leaders are responsible for responsibilities, set up a priority system for teaching . 


\section{Acknowledgement}

This research was financially supported by Beijing Teaching Reform Fund 2014, No. GJ2014006.

\section{References}

[1] Xi-Hong CHEN. Research on internationalization, informatization and humane of university teaching management at the present stage, 25 (12), Journal of chifeng institute, 2009.

[2] The Ministry of Education of the People's Republic of China. Several opinions on Comprehensively improving the quality of higher education from the ministry of education.( [2012] 4), March $16^{\text {th }}$, 2012.

[3] Adam C. Carle. Evaluating College Students' Evaluations of a Professor's Teaching Effectiveness across Time and Instruction Mode (online vs. face-to-face) Using a Multilevel Growth Modeling Approach. Computers \& Education. 2009, 53: 429-435.

[4] Jin-Qiu LIAO, Guang-Xing TAN, Xiao-Gang ZHU. Path selection of China 's university education internationalization .Chinese journal of higher education.2008, 1:59-61.

[5] Tao ZHOU, Xi-Hai YU, Yu-Xi YUAN, Chun-Qing WU. Measures to Realize Internationalization of University Education. The 11th National Annual Symposium on Industrial Technology of Economic Management Institutions, 2012, Xi'an, China.

[6] Shao-Gang ZHANG, Yong-Feng WANG. Internationalization Strategy and Policy Choice of Open Universities in China. Modern Distance Education Research. 2011, 5:9-14. 